ECCOMAS

Proceedia
COMPDYN 2021

$8^{\text {th }}$ ECCOMAS Thematic Conference on Computational Methods in Structural Dynamics and Earthquake Engineering

M. Papadrakakis, M. Fragiadakis (eds.) Streamed from Athens, Greece, 28 - 30 June 2021

\title{
BEHAVIOUR OF T-STUB UNDER MODE 2 AND 3 WITH HV AND HR BOLTS
}

\author{
Roberto Tartaglia', Mario D’Aniello ${ }^{2}$ \\ ${ }^{1}$ Department of Structures for Engineering and Architecture \\ University of Naples Federico II \\ via Forno Vecchio 34, 80136 Naples (Italy) \\ e-mail: roberto.tartaglia@unina.it \\ ${ }^{2}$ Department of Structures for Engineering and Architecture \\ University of Naples Federico II \\ via Forno Vecchio 34, 80136 Naples (Italy) \\ e-mail:mdaniel@unina.it
}

\begin{abstract}
The behavior of the bolts can strongly influence stiffness, strength, and ductility of joints. The current Eurocodes allows using both HV (German type with failure by nut striping) and HR (British-French type with failure by necking of the shank) bolts without making any distinction between them. However, recent studies showed that these two types of pre-loadable bolts are characterized by different ultimate tensile behavior that could lead different joint ductility. The aim of this work is to investigate the influence of the type of pre-loadable bolts on the behavior of T-stubs when it is subjected to mode 2 and 3. To this end, analytical and numerical analyses were carried out. The results show that only in case of the failure mode 3 some differences can be observed between $H V$ and $H R$.
\end{abstract}

Keywords: T-Stub, Seismic behavior, Bolt behavior, experimental tests, ductility. 


\section{INTRODUCTION}

The steel structures represent a viable solution in seismic areas providing a very good performance in terms of stiffness resistance and ductility [1-16]. Among then, in the recent years particular attention was given to the bolted connections that are widely used for steel structures due to both their lower constructional costs performance in terms of both resistance and ductility [8-10]. To describe the mechanical characteristics of bolted connections following the code methodology the design relies on the behavior of sub-components. Those representing the end-plate and column flange in bending are analytically modelled with equivalent $\mathrm{T}$ stub connections.

The behavior of T-stubs was widely investigated [17-26] prior to the implementation of the Component method in EN1993-1-8 [1].

The tensile behavior of the bolts plays an important role in the performance of T-stubs. Zhu et al [27] observed two additional failure modes (aside from the three currently considered in [1]) due to nut stripping in the threaded part of the bolt shank. Also D'Aniello et al. [28-29] studied the tensile behavior of European HR and HV preloaded bolts under both monotonic and cyclic loading, showing the significant difference in terms of failure mode and residual resistance. In particular, the failure mode under pure tension of HR bolts is the shank necking, while HV bolts fail under nut stripping with premature loss of strength but larger displacement capacity as respect to the corresponding HR bolts. This aspect may highly affect the T-stub ductility, which can change in function of the type of bolt, while current EN19931-8 that allows the indifferent use of both HV or HR bolts.

Therefore, in this paper the influence of the type of preloaded bolts (i.e. either HV or HR) and the effectiveness of the component method in the definition of the T-stub resistance are also experimentally investigated.

The work is organized in four main parts: in the first the design procedure, the experimental setup and the tests results are presented. The second part is focused on the comparison between the experimental results with the analytical model prescribed by the EN1993-1-8.

\section{DESIGN OF T-STUB SPECIMENS}

The geometrical and mechanical features of the T-stub specimens were designed to investigate the behavior under failure mode 2 and failure mode 3 (see Figure 1).

To achieve this purpose the geometry of the specimens was varied on the basis of the relation depicted in Figure 1, which shows that the T-Stub failure modes theoretically vary in function of the ratio $\beta$ between the tensile resistance of the bolts and sign flexural the strength related to a failure mode 1 of the connected plate $\left(4 \mathrm{M}_{\mathrm{pl}, \mathrm{Rd}} / \mathrm{m}\right)$ and the ratio $\eta$ is the ratio between the T-stub strength $(\mathrm{F})$ and the bolt tensile design resistance $\left(\mathrm{F}_{\mathrm{t}, \mathrm{Rd}}\right)$.

Each region identified in the graph corresponds to the range of features to which one failure mode is associated. As it can be observed, the normalized strength for mode 1 in case of non-circular patterns depends on the ratio $v=\mathrm{e} / \mathrm{m}$ (where $\mathrm{m}$ is the distance between the bolt axis and the web of Tee, and e is the distance between the bolt axis and the plate edge). 


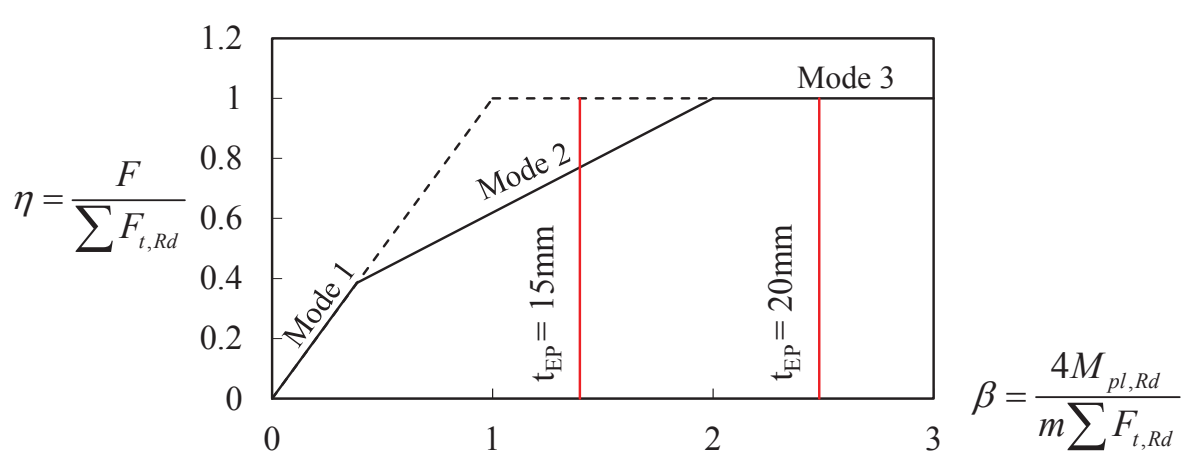

Figure 1 T-stub resistance and corresponding mechanism according to EN1993:1-8

Table 1 summarizes the experimental tests performed on the four specimens varying both the plate thickness and the bolt typologies (i.e. HR or HV). Each specimen is univocally identified by a label code with four parts that is derived from the main feature of the connection, namely:

- $\quad$ the first letter T stands for T-Stub connection;

- $\quad$ the second part identifies the type of preloaded bolt (i.e. HV or HR).

- $\quad$ the last part stands for the thickness of the flange.

The monotonic tensile tests on T-stub specimens were carried out using a universal electromechanical MTS testing machine. Tests were carried out under displacement control until failure. To prevent any damage to the test equipment that might have been induced by bolts following their failure, an encasing steel box was mounted on the web of each specimen as shown in Figure $2 \mathrm{a}$ and $\mathrm{b}$.

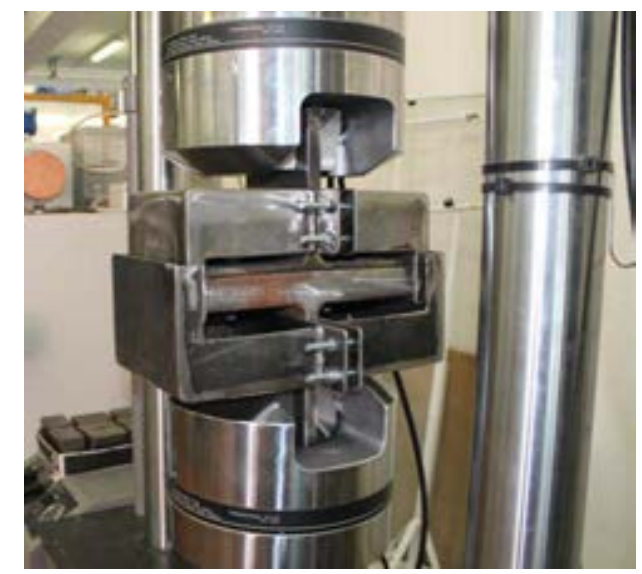

a)

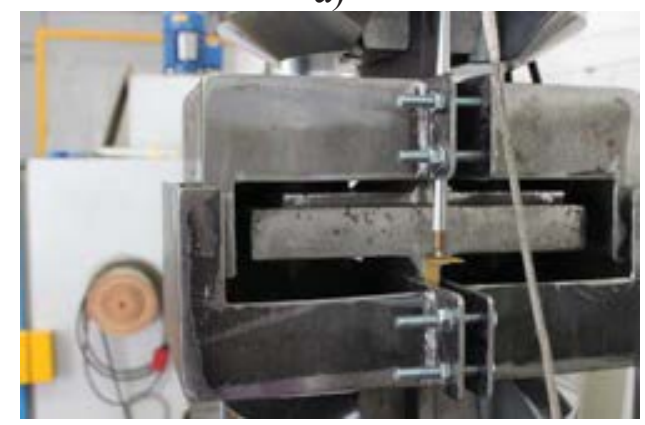

b)
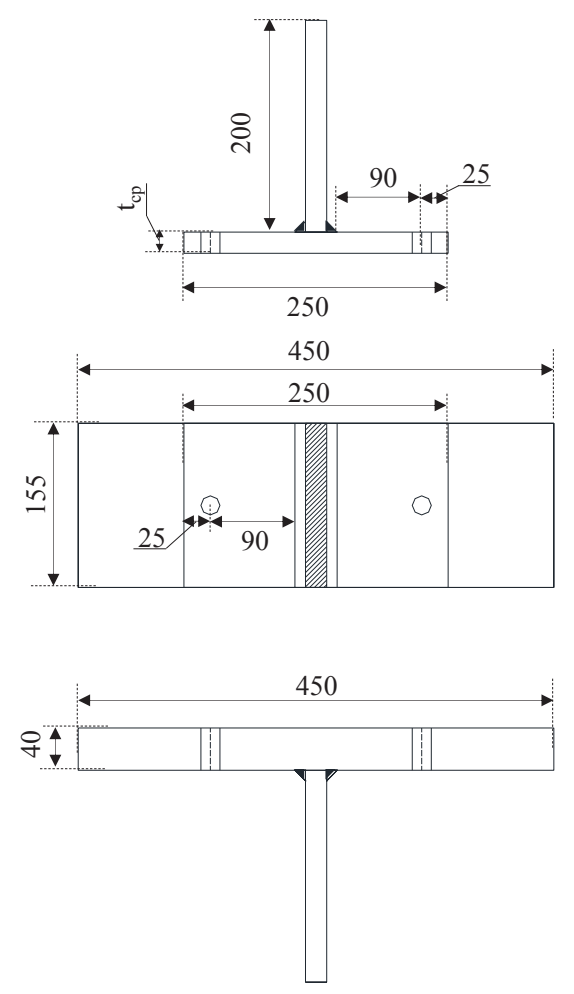

c)

Figure 2 Description $\mathrm{f}$ the experimental setup 


\begin{tabular}{cccc}
$\begin{array}{c}\text { Label } \\
{[-]}\end{array}$ & $\begin{array}{c}\text { Specimen } \\
{[-]}\end{array}$ & $\begin{array}{c}\text { Flange thickness } \mathrm{t}_{\mathrm{f}} \\
{[\mathrm{mm}]}\end{array}$ & $\begin{array}{c}\text { Bolt type } \\
{[\text { HR or HV] }}\end{array}$ \\
\hline T-HR-15 & T-15 & 15 & HR \\
T-HR-20 & T-20 & 20 & HR \\
T-HV-15 & T-15 & 15 & HV \\
T-HV-20 & T-20 & 20 & HV \\
\hline
\end{tabular}

Table 1 Experimental specimens and relative flange thickness and bolt type

\section{EXPERIMENTAL TESTS}

The experimental results are reported in terms of force-displacement curves (see Figure 3) and in terms of overall failure modes (see Figure 4). In line with the design assumptions, it can be trivially observed that increasing the thickness of the connected plate, the resistance of the specimens increases, and the failure mode moves from the flange to the bolts and ductility decreases accordingly. When a failure mode 2 is observed (e.g. see T-S-HV/HR-15), the plastic deformations are balance between the flange and the bolts; in these cases indeed large plastic deformations can be observed in the plates (see Figure $4 \mathrm{a}$ and b) and in the bolts independently from the their typologies (i.e. HR or HV). The test was stopped only at very large displacements, where the fracture in the bolts was observed (see Figure $4 \mathrm{a}$ and $\mathrm{b}$ ); it is important to observe that in both the investigated cases, all the bolts show the same failure mode due to a fracture in the shank.

Indeed, when large displacements are reached a membrane action develops in the flange, thus the bolts are not subjected only to the tensile action but also to shear. This mechanism is clearly observable in the specimens $\mathrm{T}-\mathrm{S}-\mathrm{HR} / \mathrm{HV}-15$, where the ovalization of bolt-holes is shown in Figure $4 a$ and $b$.

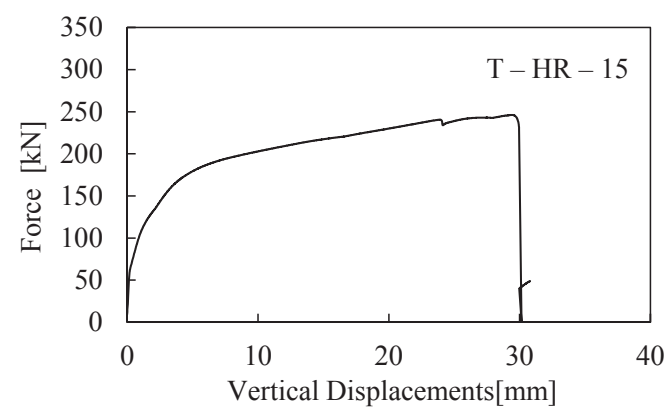

a)

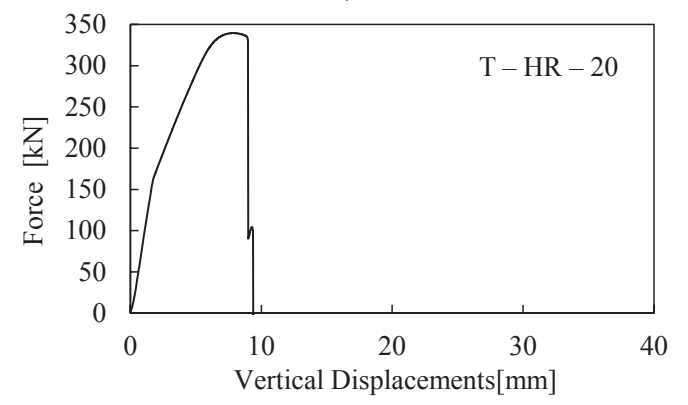

c)

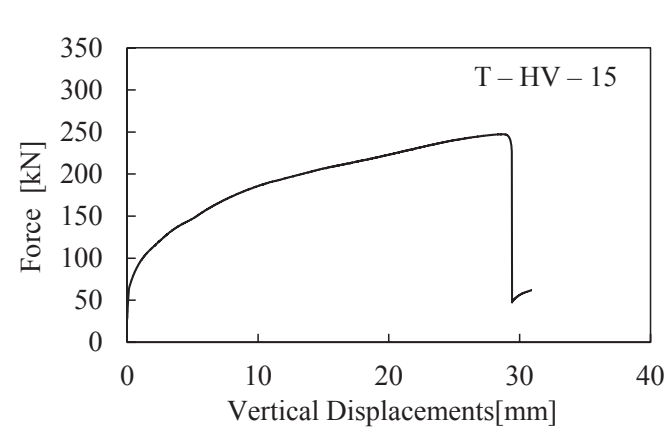

b)

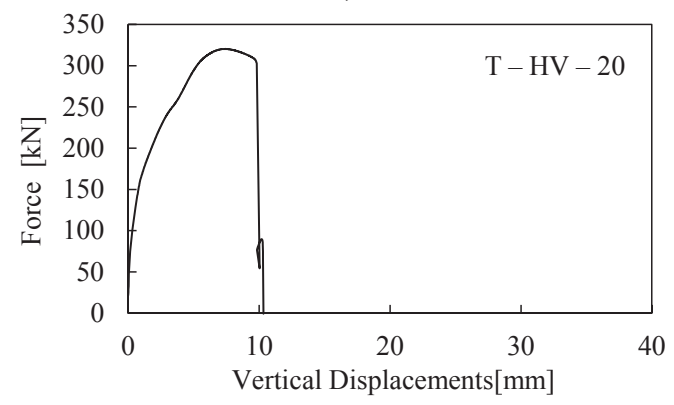

d)

Figure 3 T-stub results in terms of force displacement curve

Contrariwise, increasing the flange thickness imply a larger demand in the bolts that are mainly subjected to the tensile action without developing significant prying forces. In these cases, 
despite no appreciable differences can be observed in terms of force displacements curve, the failure of the two family of bolts is different and it is function of their typologies.

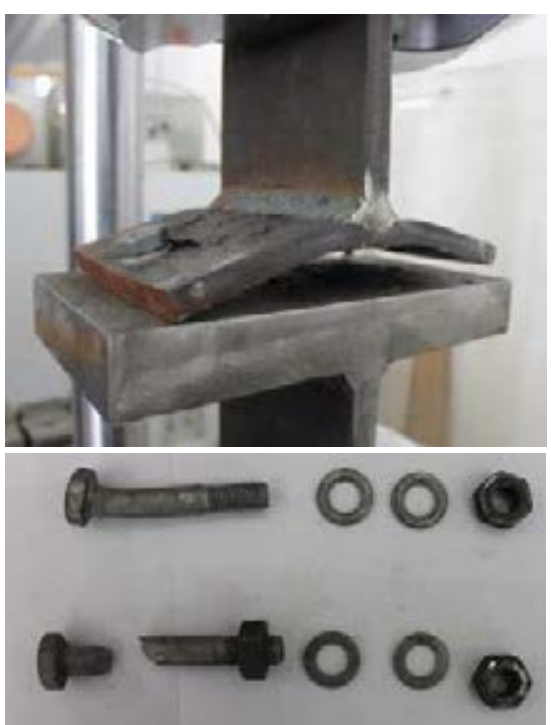

a)

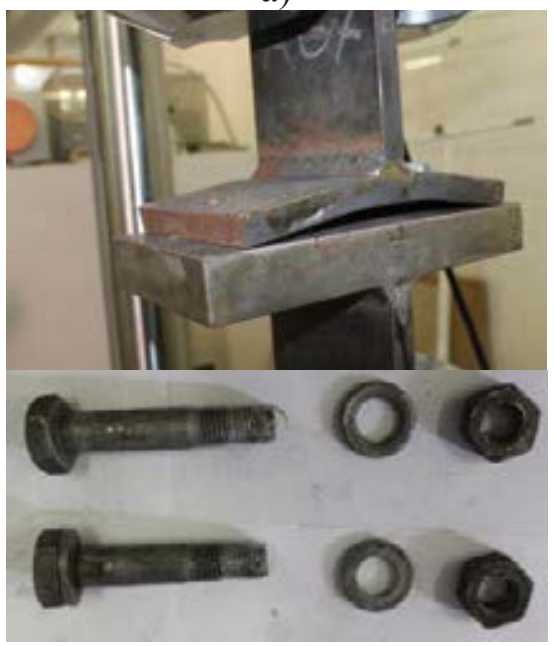

c)

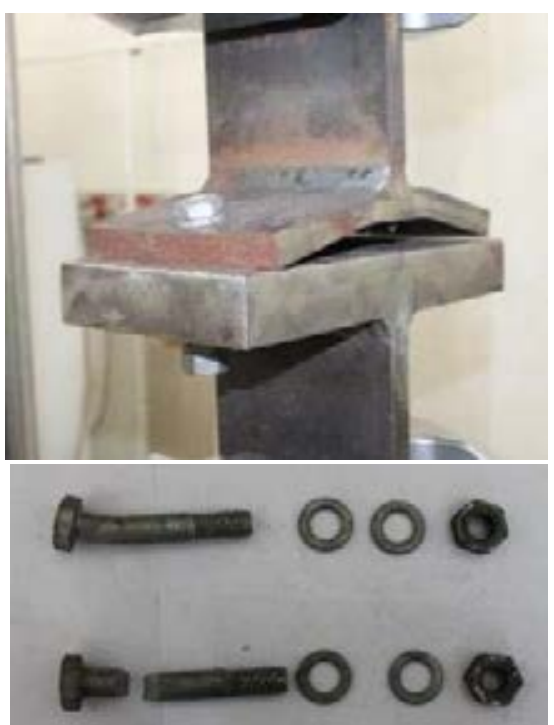

b)
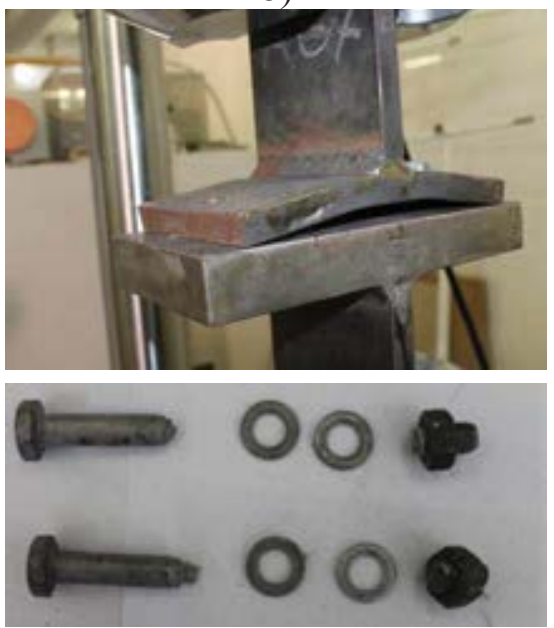

d)

Figure 4 Failure mode and bolts rupture of the investigated T-Stub

\section{CONCLUSIONS}

The influence of the type of preloaded high-strength bolts on the T-stub behaviour were investigated by means of four experimental tests.

Although the tensile failure modes of HV and HR bolts are significantly different (i.e. nut stripping and shank necking, respectively), the experimental tests showed that the mode 2 response of T-Stub connections is not affected by the different types of preloaded bolts. This result is mainly due to the type of failure exhibited by bolts that is never under pure tension, but it occurs for a combination of bending moment, axial force and shear force. Hence, HV and HR bolts can be used without any distinction when T-Stub connections are designed to experience mode 1 and 2 . 
Of course, in the case of very thick flange (i.e. when the resistance of mode 3 is about 3 times or more the resistance of mode 1) the different types of tensile failure mode of the bolts influence the residual resistance of the connection.

\section{REFERENCES}

[1] CEN 2005. CEN (European Committee for Standardization), Design of steel structures, part 1.8: Design of joints. EN 1993:1-8, Brussels, 2005

[2] G. Dell'Aglio, R. Montuori, E. Nastri, V. Piluso, Consideration of second-order effects on plastic design of steel moment resisting frames. Bulletin of Earthquake Engineering, 17(6), 3041-3070, 2019.

[3] P. Castaldo, E. Nastri, V. Piluso, Ultimate behaviour of RHS temper T6 aluminium alloy beams subjected to non-uniform bending: Parametric analysis, Thin-Walled Structures, 115, 129-141, 2017.

[4] P. Castaldo, E. Nastri, V. Piluso, FEM simulations and rotation capacity evaluation for RHS temper T4 aluminium alloy beams, Composites Part B: Engineering, 115, 124-137, 2017.

[5] V. Piluso, A. Pisapia, E. Nastri, R. Montuori, Ultimate resistance and rotation capacity of low yielding high hardening aluminium alloy beams under non-uniform bending, Thin-Walled Structures, 135, 123-136, 2019.

[6] V. Macillo, S. Shakeel, L. Fiorino, R. Landolfo, Development and Calibration of Hysteretic Model for CFS Strap braced stud walls, International Journal of Advanced Steel Construction, Hong Kong Institute of Steel Construction. ISSN 1816-112X, 14(3), 337360, 2018.

[7] A. Campiche, L. Fiorino, R. Landolfo, Numerical modelling of CFS two-storey sheathing-braced building under shaking-table excitations, J. Constr. Steel Res., 170, 2020.

[8] S. Shakeel, L. Fiorino, R. Landolfo, Behavior factor evaluation of CFS wood sheathed shear walls according to FEMA P695 for Eurocodes, Engineering Structures, 221(15) 2000 .

[9] L. Fiorino, O. Iuorio, V. Macillo, R. Landolfo, Performance-based design of sheathed CFS buildings in seismic area, Thin-Walled Structures, 61, 248-257, 2012.

[10] V. Macillo, A. Campiche, S. Shakeel, B. Bucciero, T. Pali, M.T. Terracciano, L. Fiorino, R. Landolfo, Seismic Behaviour of Sheathed CFS Buildings: Shake-Table Testing and Numerical Modelling, Key Eng. Mater. 763, 584-591, 2018.

[11] A. Campiche, Numerical modelling of cfs three-story strap-braced building under shaking-table excitations, Materials, 14(1), pp. 1-13, 118, 2021.

[12] A. Campiche, S. Shakeel, V. Macillo, M.T. Terracciano, B. Bucciero, T. Pali, L. Fiorino, R. Landolfo, Seismic behaviour of sheathed CFS buildings: Shake table tests and numerical modelling, Ingegneria sismica-International Journal of Earthquake Engineering, 35, 106-123, 2018.

[13] R. Tartaglia, M. D’Aniello, M. Andreini, S. la Mendola, The performance of preloaded bolts in seismically prequalified steel joints in a fire scenario. Materials, 13(22), 1-14, 2020 . 
[14] R. Tartaglia, M. D'Aniello, R. Landolfo, Numerical simulations to predict the seismic performance of a 2-story steel moment-resisting frame. Materials, 13(21), 1-17, 2020.

[15] R. Tartaglia, M. D'Aniello, Influence of Transvserse Beams On the Ultimate Behaviour of Seismic Resistant Partial Strength Beam-To-Colummn Joints. Ingegneria Sismica, 37(3), 50-65, 2020.

[16] M. D'Aniello, R. Tartaglia, D. Cassiano, Experimental investigation of the inelastic tensile behaviour of non-preloadable grade 8.8 bolts. Ingegneria Sismica, 37(2), 92-109, 2020 .

[17] R. Tartaglia, M. D'Aniello, M. Zimbru, Experimental and numerical study on the TStub behaviour with preloaded bolts under large deformations. Structures, 27, $2137-$ $2155,2020$.

[18] EL Minas, JG Charlis, An incremental model for predicting the mechanical characteristics of T-stub steel connections. J Mech Mater Struct, 1(7), 1135-59, 2006.

[19] A. Francavilla, M. Latour, V. Piluso, G. Rizzano, Bolted T-stubs: A refined model for flange and bolt fracture modes. Steel and Composite Structures, 20, 267-293, 2016.

[20] C. Faella, V. Piluso, G. Rizzano, Experimental analysis of bolted connections: Snug versus preloaded bolts, J. Struct. Eng., 124(7), 765-774, 1998.

[21] J.A. Swanson, R.T. Leon, Bolted steel connections: Tests on T-stub components, J. Struct. Engrg., ASCE, 126(1), 50-56, 2000.

[22] J.A. Swanson, R.T. Leon, Stiffness modeling of bolted T-stub connection components, Journal of Structural Engineering, 127, 2001.

[23] M. Latour, G. Rizzano, Experimental Behavior and Mechanical Modeling of Dissipative T-Stub Connections, J. Struct. Eng., 138(2), 170-182, 2012.

[24] J. Ribeiro, A. Santiago, C. Rigueiro, L.S. Da Silva, Analytical model for the response of T-stub joint component under impact loading, Journal of Constructional Steel Research, 106, 23-34, 2015.

[25] M. Latour, G. Rizzano, A. Santiago, L.S. Da Silva, Experimental analysis and mechanical modeling of T-stubs with four bolts per row, Journal of Constructional Steel Research, 101, 158-174, 2014.

[26] A.B. Francavilla, M. Latour, V. Piluso, G. Rizzano, Simplified finite element analysis of bolted T-stub connection components, Engineering Structures, 100, 656-664, 2015.

[27] Xulin Zhu, Peijun Wang, Mei Liu, Wulan Tuoya, Shuqing Hu, Behaviors of one-side bolted T-stub through thread holes under tension strengthened with backing plate, Journal of Constructional Steel Research, 134: 53-65, 2017.

[28] M. D’Aniello, D. Cassiano, R. Landolfo, Monotonic and cyclic inelastic tensile response of European preloadable GR10.9 bolt assemblies, Journal of Constructional Steel Research, 124: 77-90, 2016.

[29] M. D’Aniello, D. Cassiano, R. Landolfo, Simplified criteria for finite element modelling of European preloadable bolts, Steel and Composite Structures, 24(6), 643-658, 2017. 